\title{
COMMUNITY SERVICE TEACHER WORKING GROUP (KKG) VALUES OF THE NATION IN BUILDING CHARACTERS IN THE ELEMENTARY SCHOOL OF BANDUNG CITY
}

\author{
Siti Sholiha Nurfaidah ${ }^{1}$, Devi Rahmiati ${ }^{2}$, Lukman Azis Praja ${ }^{3}$ \\ ${ }^{123}$ PGSD FKIP Universitas Pasundan,Bandung,Indonesia \\ ${ }^{1}$ sitinurfanurfaidah@unpas.ac.id, ${ }^{2}$ devirahmiati@unpas.ac.id, ${ }^{3}$ azisunpas@ gmail.com
}

\begin{abstract}
Education that integrates character education in the learning process oriented towards the formation of the child as a whole human being. Therefore, character education can not be excluded.As for the impact of rapid globalization, resulting in decreased values of the nation's character. Upaya solving these problems is to provide guidance in enhancing the ability of educators in shaping the character of the nation's values of elementary school students. Goal of this activity is the Teachers Working Group (KKG) in SD BPI and KKG in SDN 208 Luginasari.The method used in the form of seminars and workshops in the form of knowledge and skills to carry out learning activities that includes character education through the medium of the traditional game. Then do the teacher mentoring in order to ensure that they practiced with good results briefing in seminars and workhsop has done. Mentoring is very useful because many intertwined transfer of knowledge between teachers and Service Team. PKM activity can be said to have contributed to the development of character values of the nation. However, such activities still need to be disseminated to a wider audience.
\end{abstract}

Keywords: Teachers Working Group (KKG), a national character, traditional games.

\section{A. Introduction}

The progress of a nation is determined by the ability of its educators to shape the character of future generations. Without educator figures, maybe a big nation like Indonesia would not be Able to enjoy the results of the Efforts of the sons and daughters of the archipelago who have of Indonesia to date is Inseparable from the role of the teacher who has guided his students to Become adults and play an active role in the development of Indonesia. Therefore, the task Carried by a teacher is not easy, Because The teacher is not only a facilitator in transferring knowledge. Even According to Ma'mun, Abin. (2004) the duties and roles of teachers include as 
a conservator (the preserver), transmitter (successor), transformers (translator) and organizer (implementer) of life value systems.

The quality of education is very influential on the quality of human resources. Teachers have a very important role in improving the quality of education in schools, especially at the level of basic education that provides students the ability to equip with basic knowledge and skills. As Suaidinmath (2014) states that improving teacher management is a paradigm for the underlying quality of education. Therefore, the ability or competence of teachers needs to be fostered and improved, so that in carrying out their duties and responsibilities can create an optimal performance of educators and can improve Reviews their competence. As an effort to foster or improve the ability of teachers in primary schools one of them is through the formation of Teachers Working Group (KKG).

Based on the explanation above, the values of the nation's character in the students can also be built through the development of KKG. Our target group is the $\mathrm{KKG}$ in the center of Bandung. Bearing in mind that the influence of western culture in the urban environment is Sufficiently Dominating so that it has an impact on the emergence of problems of decreasing the values of the nation's character as follows:

a. Traditional games are Increasingly extinct

The rise of the modern games, video games, or various other computer-based games has made our children switch from traditional games. Not to mention that now Reviews those games are getting closer to the grasp and more affordable, through various games on communication devices (mobile phones). Technology is indeed a good thing. However, technologybased games turned out to Contain many elements of high-level violence. In the country of the game makers, the game is actually intended for adults. However, the lack of filters and supervision from parents makes the game penetrate into the world of children's games. This will certainly have a negative effect on children's development, both physically, psychologically, socially, and other developments.

b. Knowledge of traditional games is getting low 
Games such as marbles (marbles), kite (Kites), top (tops),gobak Sodor (Sodor carts), hide and seek(Hide-and-seek), dakonan, etc. are traditional games that are foreign to today's children. Maybe some of them ask "Sodor gobak of what it is, Dakonan like what?" Phenomena like this must be found. So it should be a concern, that the knowledge of traditional games is very low and maybe they are Easier to Recognize and explain the modern games that they Often wrestle with Reviews their respective phonemes.

c. The lack of traditional infrastructure game

A variety of fun and more promising facilities are Easily Obtained in modern games. The existence of Reviews These facilities is preferred by children Because it is Easier and more practical. Whereas the current infrastructure of traditional games is very limited. Given the willingness of land to play displaced by urban buildings causes children to have to play indoors.

d. There is no law that preserves the traditional game

As we know, Indonesia has many traditional games, the which have many benefits in developing the nation's character. It would be very unfortunate if a traditional game that has noble values and is one of the characteristics of the Indonesian people claimed by other nations as their traditional game. Like the lumping horse game that has been claimed by Malaysia. Therefore a law is needed to protect it so that traditional games are not claimed by other countries.

\section{e. Modern games are asocial}

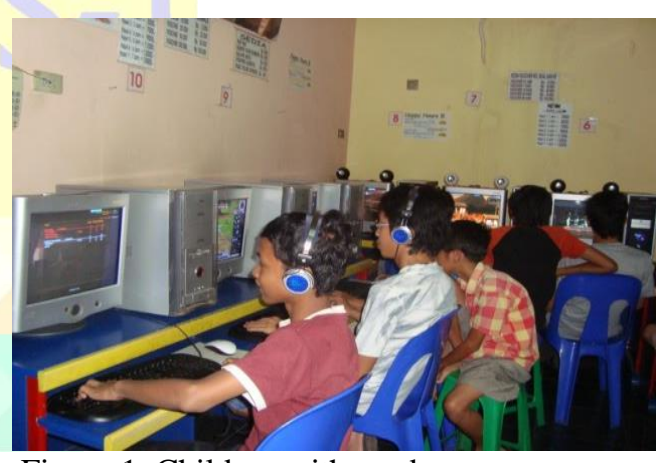

Figure 1. Children with modern games

Above shows that modern games shape children into individualists. Even though they sit next to each other, but they do not berinteraksi with each other. Modern computer / gadget-based games of make children growing niche to be asocial Because It is enough to be played alone in front of Reviews their computers or Androids.

$f$. Modern games have a negative impact on health 
Modern play patterns that growing niche to direct children to sit for hours at a computer or gadget have a negative influence on health, Including eye health disorders, Decreased brain activity, Disrupting children's sleep patterns, risk of contracting hemorrhoids or hemorrhoids, reduced metabolism, obesity, and osteoporosis.

g. Modern games limit the actualization of children

Children who play modern games will tend range to focus and not do anything especially physical activity. Therefore, parents' wisdom is needed by directing Reviews their children to switch to traditional games. The following is an illustration of the involvement of physical and motorcycle activities intraditional games.

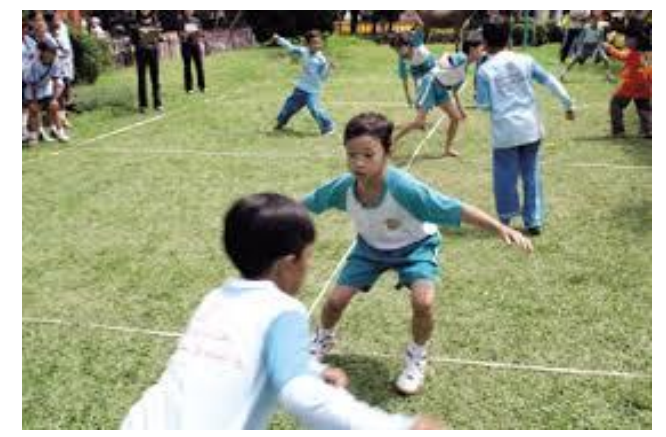

Figure 2 Physical Activity in Traditional Games

The traditional game as shown in Figure 2 above, is able to improve the movement system in children in order to educate children to Become healthy and strong individuals.

h. Modern games limit children's creativity

Traditional games teach children to be creative. In some kinds of games, supporting facilities and infrastructure are needed, so children are encouraged to be creative in creating tools such games such as stilts from bamboo, toy cars from orange peels, and many others. This is in contrast to the modern games that provide everything instantly.

i. Modern games tend range to lead children to consumptive patterns The availability of complete and adequate facilities is certainly the main attraction for children. However, it all can not be Obtained free of charge. They have to pay a few Rupiahs to be Able to play. In the end, children will be led to a pattern of consumptive life.

j. Loss of National Character The loss of traditional games Also means the loss of national character values. Traditional games are actually as old as the age of the culture in our country. They are an 
Inseparable part of the culture. Indonesia, the which is very rich in various cultural heritage, is very rich in various traditional games. Traditional games Also teach the values of cooperation, sportsmanship, honesty, and creativity. Not to mention some games that sometimes negative Contain contents, such as elements of violence, SADISM and pornography.

\section{B. Method of Implementation}

The method used in this community service activity is in the form of conducting seminars on the role of teachers in enhancing the values of the nation's character to elementary school students and carrying out workshops to create an implementation plan (RPP) that inserts traditional games in order to build and improve and Realize the Character Education program "Bandung MASAGI" the which is Appropriate and in line with Curriculum 2013 without leaving the values of the Sundanese character.

The stages of implementation of community service are as follows:

\section{Preparation Stage}

a. Observation
Observations were made by the community service team with the aim to find out the Preliminary Data about the potential role of teachers in introducing traditional games in enhancing the values of national character, especially in elementary school students in the city of Bandung, which was conducted by interviewing relevant parties to the two partners.

b. Coordination

Coordinating the two partners to conduct seminars, workshops and mentoring to the relevant parties (Principals and Teacher Working Groups) in this community service activity.

c. Determination of the Seminar and Workshop Activities

In collaboration with the School Principal, the planning of seminars and workshops includes the determination of the committee, seminar and workshop schedules, time and place of seminars and workshops, seminar materials, and assistance or workshop schedules as stated and implicit in the Memorandum of Understanding ( MoU) made by both parties Involved in this community service activity. In addition, the team worked with outsiders such as the Bandung City 
Education Office to contact the relevant speakers with the title and purpose of this community service activity so that the activity can be Carried out properly.

d. Preparation of the Seminar and Workshop Materials

Arranging seminars and workshop materials the which include the role of the teacher in introducing the influence of the game in developing the values of the nation's character, forming and directing the game, especially traditional games, in enhancing the values of the nation's character in accordance with the 2013 Curriculum and the Mayor of Bandung regulations on Character Education designation known as "Bandung MASAGI".

\section{Implementation Stage}

The community service activity program seminar was Carried out using the lecture method, interactive discussions, and continued with a workshop on making lesson plans that insert traditional games. As for the speakers who were presented apart from the service team were Several initiators of the Mayor Regulation (Perwal) on Character Education "Bandung MASAGI", one of which was at the same time a leader at the Eco Bamboo Cipaku Bandung the which is engaged in preserving Sundanese culture.

Subsequent service activities are mentoring to school teachers in the application / practice of the results of the debriefing in the previous seminars and workshops. Assistance was Carried out 3 times.

\section{Evaluation Phase}

Evaluation is done by examining the results / documentation of seminars and workshops on the role of the teacher in shaping and directing the game, especially traditional games, in enhancing the values of the nation's character by the team proposing community service activities.

\section{Result and Discussion \\ 1. Result}

Based on mutual agreement, seminar and workshop activities were held on Saturday, July 21, 2018. Participants who Attended the seminar consisted of elementary school teachers BPI, 208NN Luginasari Sukagalih teachers, lecturers UNPAS FKIP, and FKIP UNPAS students. In addition, the activity was Carried out Because it was supported by the 
committee (both lecturers, students, and FKIP UNPAS staff) and this seminar invited speakers (PKM team and practitioners), so that all of the performers consisted of \pm 70 people.

Figure 3. Photo together at the Seminar

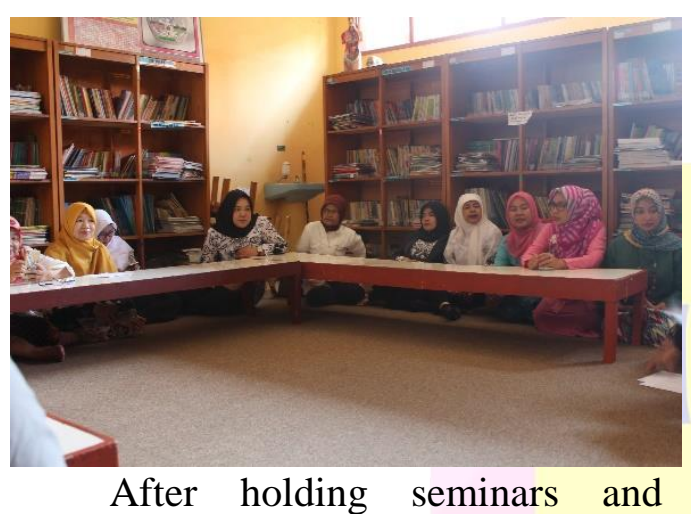

workshops, applications are then made of the provision of knowledge that has been Described in previous activities. The application of knowledge by the teacher concerned was accompanied by the entire PKM TEAM. This activity is called mentoring activities. Assistance was Carried out 3 (three) times during the PKM period which was Carried out in each partner school, consisting of: 1) The first assistance is Carried out in order to introduce traditional games to students for the preservation of the nation's character values. The teacher practices in the results of the learning design inserts that traditional games that have been made. The first assistance was Carried out on July 25, 2018.

2) The second assistance that is Carried out is the management and development of the infrastructure that supports the implementation of the objectives of this service. By adjusting to the strengths and weaknesses that

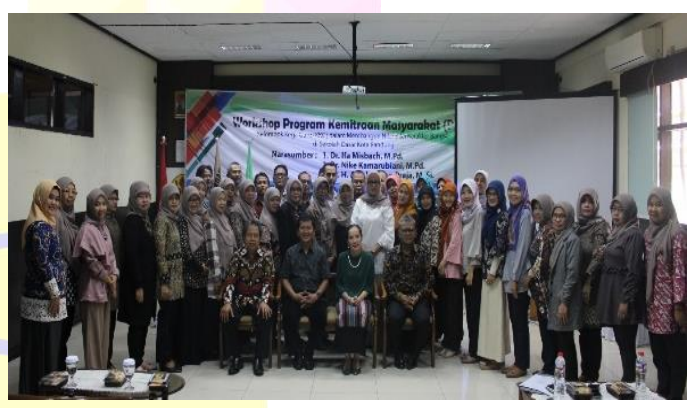

exist in schools. This assistance has been Carried out on Thursday, November 1, 2018 in each partner school. The development of infrastructure is strengthening the management of infrastructure that is already available.

Figure 4 Traditional games without tools

3) The 3rd assistance was Carried out on Wednesday 7 November 2018 the which focused on monitoring and evaluating the implementation of learning the which included traditional games. There was a discussion between the teacher and the service team related to the traditional games in learning. Then, we confirm each other what can Appear character values in each type of 
traditional games and how Reviews These values can be internalized in students' personalities.

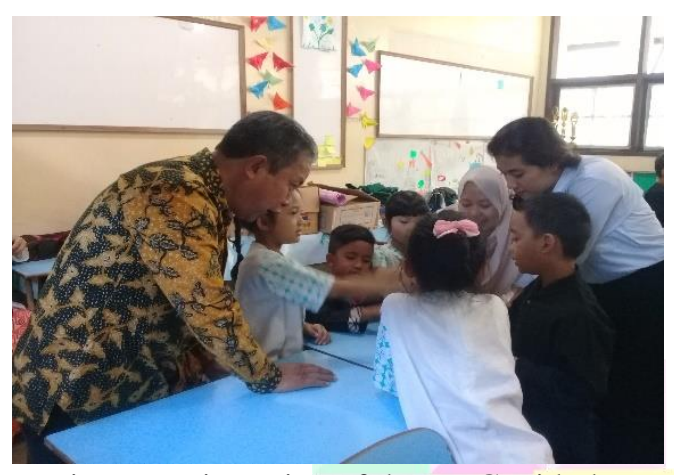

Figure 6 Discussion of the KKG with the Dedication Team

\section{Discussion}

This dedication was Carried out activity based on an analysis of the global situation that there was a decline in morale and character of the nation due to technological advancements and information. Then the situation analysis was Carried out specifically for our two partners who Showed a Similar phenomenon. So rather than that, one of the Efforts to build the values of this nation's character is through the process of teaching and learning in formal education. The teacher as a facilitator at school certainly has to know far more than the students. For this reason, the service program activities are the socialization of the teacher's role in Efforts to build the nation's character values through traditional games to students in the school environment through seminars, workshops and mentoring.

Based on the results of a UNICEF study, 2014 (Kamarubiani, 2018) stated that 30 million Indonesian children aged 10-19 years are internet users. Most of them are exposed to pornographic content, when it appears accidentally or in the form of vulgar advertisements. In addition, parents in Indonesia Reviews their children lag behind in mastering digital media. A Similar phenomenon was Also Obtained from the results of a study by the Foundation of Kita and Baby, 2013 (Kamarubiani, 2018) that $76 \%$ of 2,818 grade 4-6 elementary school students had accessed pornographic material online through mobile devices, especially through smartphones. The impact of pornography is Believed to be closely related to an Increase in cases of sexual violence in children. moreover, the tendency of sexual violence perpetrators are Reviews those who are accustomed to consuming porn videos. This was further strengthened by cases of sexual violence that have Increased from year to year According to the data from the Child Protection Commission in 2010- 
2014 (Kamarubiani, 2018), such as: 1,407 cases occurred in $2011 ; 1,635$ cases in 2012; da 2,070 in 2013. This certainly has Become a real picture that Indonesia is being faced with the threat of moral degradation. This kind of thing can not continue to be left until it Becomes Increasingly complicated. We as educators need to come down directly in Overcoming this problem. 407 cases occurred in $2011 ; 1,635$ cases in 2012; da 2,070 in 2013. This certainly has Become a real picture that Indonesia is being faced with the threat of moral degradation. This kind of thing can not continue to be left until it Becomes Increasingly complicated. We as educators need to come down directly in Overcoming this problem. 407 cases occurred in 2011; 1,635 cases in 2012; da 2,070 in 2013. This certainly has Become a real picture that Indonesia is being faced with the threat of moral degradation. This kind of thing can not continue to be left until it Becomes Increasingly complicated. We as educators need to come down directly in Overcoming this problem.

Seminars and workshops are used as one method in resolving the problem of the decline in the nation's character values. The activities emphasized more on the socialization of the teacher's role in shaping the values of the nation's character through traditional games. In this activity, the Bandung MASAGI program, the which is a character-based character education model, the values of local wisdom. The vision of this program is "Realizing Bandung City students who have superior character, morality, love of the motherland, care for the environment and Sundanese culture, the which is based on the philosophy of hone, hone, hone, and wawangi." Program 'Bandung MASAGI'

Besides that, It is also explained the national character values that can be built from a traditional game. As well as in this activity, it is emphasized the need for a program that can establish cooperation and harmony of educational programs in education units, families and communities as a tri-center of education in building an educational ecosystem conducive to fostering character and culture of achievement for students.

In addition to the seminars, the next set of community service activities was a workshop. The workshop was held on the same day after the seminar process was finished. This workshop 
consists of the preparation of the lesson plan (RPP), the which includes traditional games. Other activities include assistance. The assistance Referred to is the application / practice of the provision of knowledge and skills that have been Described in seminars and workshops. This assistance was Carried out in each partner school. This activity was very good and received Considerable attention than the teachers in each partner school. They can discuss and confirm with each other about the values contained in the traditional games that they insert in the learning process.

\section{Conclusion}

The Community Partnership Program against Teacher Working Group (KKG) in Bandung Elementary Schools through traditional games has Contributed to the development of national character values. However, similar activities still need to be disseminated to a wider audience not focused on the Teacher Working Group in urban areas only. Considering that there are many teachers who do not remember the traditional games they experienced. And many young teachers who did not experience the traditional games in their childhood.

In addition, character development can still be done through a different approach, not only through the preservation of traditional games. This is so that national character values can still be developed and preserved more broadly, not limited to Certain approaches. So that the impact of globalization that is getting stronger is not easy to wear off the values of the nation's character that we should keep forever.

\section{REFERENCES}

Agustin, M, \& Syaodih. (2008). BimbiNgan Counseling for Early Childhood. Jakarta: The Open University.

Kamarubiani, Nike. (2018). Best Practice Partnership with Schools Art Workshop in Character Education Program. Materials views seminar: Unpublished

Ma'mun, Abin. (2004). Educational Psychology. Bandung: Rosda paper

Miftah. (2016). Bandung MASAGI appreciated by the Education Minister. Available. [on line]:https://portal.bandung.go.id /posts/2016/07/19/LVEY/bandu ng-masagi-diapresiasimendikbud, (August 20th 2018) 
Praja, Aziz et al .. (2018). PKM

Teachers Working Group (KKG)

in Building a National Character Values in Primary School in Bandung, West Java Province, Final Report Year PKM. Unpublished.

Suaidinmath. (2014). Role of Teachers to Improve the Quality of Education.Available. [on line]: https://suaidinmath.wordpress.co m/2014/09/10/peranan-guruuntuk-meningkatkan-kualitaspendidikan/

Zahroh, Fatim. (2017). Importance of Character Education in Education.Available. [on line]:https://www.kompasiana.co $\mathrm{m} /$ fatiiim/590ff69fa5afbd8508fef9 94/pentingnya-pendidikankarakter-dalam-dunia-pendidikan, (August 20th 2018) 
